\title{
Icariin Restores Bone Structure and Strength in a Rat Model of Chronic High- Dose Alcohol-Induced Osteopenia
}

\author{
Jie-Zhou Wua Peng-Cheng Liu ${ }^{a}$ Run Liub Ming Cai ${ }^{\mathrm{a}}$ \\ aDepartment of Orthopedics, Shanghai Tenth People's Hospital, School of Medicine, Tongji University, \\ Shanghai, ${ }^{b}$ Department of Orthopedics, Affiliated Hospital of Chengdu University, Chengdu, P.R. China
}

\section{Key Words}

Alcohol-induced osteopenia • Icariin • Bone biomechanics • Bone histomorphometry

\begin{abstract}
Background/Aims: Chronic alcohol abuse is an important risk factor for osteopenia. However, few studies have focused on the efficacy and mechanism of action of icariin on alcohol-induced osteopenia. The aim of this study was to investigate the efficacy and underlying mechanism of action of icariin in the treatment of chronic high-dose alcohol-induced osteopenia in a rat model. Methods: Thirty-six adult male Sprague-Dawley rats were randomly divided into four groups: sham, alcohol, and low-dose and high-dose icariin groups. Bone volume fraction $(\mathrm{BV} / \mathrm{TV})$, bone mineral density (BMD), bone biomechanical properties, and bone morphology were assessed after 16 weeks. Reverse-transcription PCR was used to detect mRNA expression levels of alkaline phosphatase (ALP), collagen type I (Col I), osteocalcin (OC), runt-related transcription factor 2 (Runx2), bone morphogenetic protein-2 (BMP-2), and osteoprotegerin (OPG). Results: Bone metabolic markers and biomechanical properties in the alcohol group were decreased significantly compared with the sham group. BV/TV, BMD, mineral apposition rate (MAR), percent trabecular area (\%Tb.Ar), and bone biomechanical properties were elevated in the low-dose and high-dose icariin groups relative to the alcohol group. ALP, Col I, OC, Runx2, BMP-2, and OPG mRNA levels in the icariin group were significantly elevated in comparison with the alcohol group. Conclusion: Icariin can prevent overall progression of chronic high-dose alcohol-induced osteopenia in a rat model, in a dose-dependent manner. Icariin promotes bone formation and inhibits bone loss, and effectively restores bone structure and strength in chronic high-dose alcohol-induced osteopenic rats. Bone metabolism reversal is evidenced by increased BV/TV, BMD, MAR, \%Tb.Ar, and biomechanical properties and elevated ALP, Col I, OC, Runx2, BMP-2, and OPG mRNA levels.
\end{abstract}

\section{Introduction}

Ethanol is the principal psychoactive constituent in all alcoholic beverages. Heavy alcohol consumption has become a common health and social problem of modern society. J.-Z. Wu, P.-C. Liu and R. Liu contributed equally to this work. 


\section{Cellular Physiology Cell Physiol Biochem 2018;46:1727-1736 \\ \begin{tabular}{ll|l} 
DOI: 10.1159/000489248 & and Biochemistry \\
Published online: April 26, 2018 & $\begin{array}{l}\text { O } 2018 \text { The Author(s). Published by S. Karger AG, Basel } \\
\text { www.karger.com/cpb }\end{array}$ \\
\cline { 2 - 3 }
\end{tabular}}

Alcohol is detrimental to many tissues and organs, including bone [1]. A large-scale casecontrol study in Denmark [2] revealed an alcoholism rate of $7.1 \%$ in patients with fractures versus only $2.5 \%$ in control subjects without fractures. A cross-sectional study of 431 men in Spain revealed the prevalence of alcohol intake as a risk factor in $30.9 \%$, being the most common risk factor for osteoporosis in men in this study [3]. A recent French study [4] detected alcoholism as a risk factor for osteoporosis in $28.1 \%$ of men; another French study [5] found $22.5 \%$ of men with alcoholic osteoporosis. In general, most studies have shown that alcohol is an important risk factor for osteoporosis in men.

The pathogenesis of alcoholic osteoporosis is not yet fully understood [6]. The etiology of alcohol-related bone disease is multifactorial [1, 6], and the effect of alcohol on bone is considered to be both direct and indirect. Alcohol has a direct impact on the activity of bone cells. Under the influence of alcohol, bone marrow mesenchymal stem cell growth and transformation to osteoblasts are inhibited [7]. Alcohol can induce bone marrow mesenchymal stem cells to differentiate into fat cells [8]. In addition, alcohol inhibits the growth of osteoblasts in a dose-dependent manner in cell culture [9-12]. Gonadal hormone production is affected by the amount of alcohol consumed. In men, low levels of testosterone can be seen regularly. Moderate drinking can increase the production of estrogen, so may be an important protective factor in the case of low alcohol intake. Increased bone mineral density due to low alcohol intake may even be explained by elevated estrogen levels. Recent studies, however, have reported novel mechanisms by which alcohol may affect bone remodeling, including apoptosis, oxidative stress [13], and regulation of the Wnt signaling pathway $[14,15]$.

Osteoporosis is the most common progressive bone disease, and is characterized by a decrease in bone mass and bone density, which leads to an increased risk of osteoporotic fractures, a high risk of disability, and increased health and economic costs [16, 17]. In 2010, 5.5 million men were diagnosed with osteoporosis in the European Union [18]. Osteoporotic fractures are a major public health problem in China and the economic burden of such fractures on Chinese patients and the country is heavy [19]. The etiology of osteoporosis can be idiopathic or secondary to gonadal hypofunction, lack of vitamin D, insufficient calcium intake, or long-term excessive drinking, eventually leading to increased risk of osteoporosis. To date, few studies have investigated icariin therapy in chronic high-dose alcohol-induced osteopenia. In this context, only bisphosphonates and vitamin D supplementation were used to prevent bone destruction and bone toxicity related to alcohol abuse in mice [20,21]. Many herbs used in traditional Chinese medicine have been tested for their effects on osteoporosis in the laboratory and in the clinic $[22,23]$. Icariin is isolated from Herba epimedii and used for the treatment of kidney, liver, and joint disorders [24, 25]. Most studies found that icariin prevented bone loss in vitro and restored femur strength in vivo [26-28]. It can fully suppress the decrease in estrogen concentration in serum, and also partially restore uterine weight in ovariectomized rats [27, 29]. A 2-year randomized controlled trial showed that extracts containing $60 \mathrm{mg}$ icariin, $15 \mathrm{mg}$ daidzein, and $3 \mathrm{mg}$ genistein can prevent bone loss in postmenopausal women [30]. The findings of a study by Liu et al. suggested that icariin can promote proliferation and differentiation in osteoblasts exposed to an overloaded mechanical environment [31]. Although accumulating evidence indicates that icariin promotes osteoblast and bone formation, the specific molecular mechanism of action of icariin is still unknown. We evaluated the therapeutic effect of icariin in a chronic high-dose alcohol-induced osteopenic rat model and examined the underlying mechanism of action.

\section{Materials and Methods}

\section{Animals}

The research was carried out in the Laboratory Animal Center of the Shanghai Tenth People's Hospital after approval from the hospital ethics committee. The animal model was carried out in strict accordance with the guidelines of the Shanghai Laboratory Animal Center and the policy of animal use of the Shanghai 


\section{Cellular Physiology Cell Physiol Biochem 2018;46:1727-1736

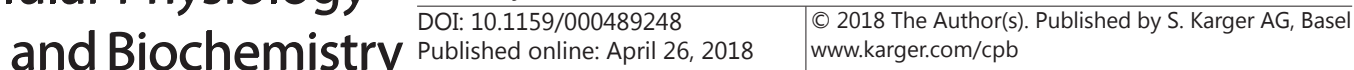

Wu et al.: Icariin Restores Bone Structure and Strength of Alcohol Induced Osteopenia

Tenth People's Hospital. The protocol was approved by the Animal Care and Welfare Committee of Tongji University.

Thirty-six adult male Sprague-Dawley rats provided by Shanghai SLAC Laboratory Animal Inc. that were fed a standard diet (GB14924.2 - GB14924.6) with a mean body weight of $563 \mathrm{~g}$ (range 548-587 g) and a mean age of 30 weeks were randomly divided into four groups (sham, alcohol, and low-dose and high-dose icariin groups; $\mathrm{n}=9$ per group) by means of a random number table. Rats were adapted to the laboratory environment (temperature, $18-22^{\circ} \mathrm{C}$; humidity, $65 \pm 5 \%$ ) for 1 week before the experiment.

\section{Treatment}

All rats were housed and reared at the specific pathogen-free laboratory animal experimental center of the Shanghai Tenth People's Hospital. Alcohol-induced osteoporosis model was induced in rats for 24 weeks, with daily gavage of $42 \%(\mathrm{v} / \mathrm{v})$ ethanol $(7.5 \mathrm{~g} / \mathrm{kg})$. Body weight of the animals was recorded daily during the experimental period to determine the amount of ethanol required. Due to the low caloric content of ethanol and its appetite suppressant effect, an isocaloric ethanol-free liquid diet were fed to all rats [32]. According to two previous studies [33, 34], we performed a dose-response experiment with $42 \%$ (v/v) ethanol $(2.5,5,7.5$, and $10 \mathrm{~g} / \mathrm{kg})$ once daily. We found that rats administered $42 \%(\mathrm{v} / \mathrm{v})$ ethanol $(7.5 \mathrm{~g} / \mathrm{kg})$ once daily were neither drunk nor lethargic, but significant bone loss was induced. Thus, rats in the alcohol group were treated with $42 \%(\mathrm{v} / \mathrm{v})$ ethanol $(7.5 \mathrm{~g} / \mathrm{kg})$ once daily in the morning and isocaloric ethanolfree liquid diet in the afternoon. Icariin powder with a purity of more than $98 \%$ (high-performance liquid chromatography) was purchased from Sigma-Aldrich. Rats in the low-dose icariin group received $42 \%$ (v/v) ethanol $(7.5 \mathrm{~g} / \mathrm{kg}$ ) once daily in the morning and icariin-containing suspension $(2 \mathrm{mg} / \mathrm{kg})$ with isocaloric ethanol-free liquid diet in the afternoon. Rats in the high-dose icariin group received $42 \%$ (v/v) ethanol (7.5 $\mathrm{g} / \mathrm{kg}$ ) once daily in the morning and icariin-containing suspension $(4 \mathrm{mg} / \mathrm{kg}$ ) with isocaloric ethanol-free liquid diet in the afternoon. Rats in the sham group received the isocaloric ethanol-free liquid diet once daily in the afternoon.

After 24 weeks, anesthetized rats were killed by cervical dislocation. A whole blood sample (10 ml) was collected from each rat via the femoral artery and immediately stored at $-70^{\circ} \mathrm{C}$ for reverse transcription PCR (RT-PCR) analysis. The leg was amputated from the hip joint, and the femur and lumbar vertebra were stripped of soft tissues and stored at $-70^{\circ} \mathrm{C}$ for biomechanical testing, micro computed tomography (micro$\mathrm{CT}$ ), and bone morphological evaluation.

\section{Radiological evaluation}

Serial micro-CT scans of the right femur were carried out using a micro-CT scanner (Skyscan1172, Bruker) according to a previously reported protocol [35]. Briefly, the region of interest (VOI) was the metaphysis extending 1.5--3.5 mm proximally from the distal growth plate cartilage of the femur. An average of $1.82 \mathrm{~mm}^{2}$ of cancellous bone tissue was measured in each set of six femur sections. The bone volume fraction (BV/TV) of trabecular and cortical bone in femur was calculated along with trabecular number (Tb.N), trabecular thickness (Tb.Th), and trabecular separation (Tb.Sp) [36], then bone mineral density (BMD) was calibrated using the attenuation coefficient of two hydroxyapatite phantoms with defined BMD of 0.25 and $0.75 \mathrm{~g} / \mathrm{cm}^{3}$. After micro-CT scanning, acetone-fixed tissue plugs of femur corresponding to the above-mentioned VOIs were further processed for histological analysis. Serial sections were made ( $5 \mu \mathrm{m}$ thickness) for microscopy of the femur with tetracycline fluorescence double labeling (twice at an interval of 2 weeks according to the protocol; the last time 2 days before the rats were killed) and toluidine blue staining. Evaluations were conducted by an expert blinded to the group and findings from micro-CT scanning. Mineral apposition rate (MAR) and \% Tb.Ar were assessed using Image-Pro Plus version 5.0. Briefly, at least five sections from each sample were stained for analysis. For each section, five areas were measured.

\section{Biomechanical testing}

Based on related studies and a previous protocol [37-40], all left femoral and L4 lumbar vertebra from rats were stored in separate sealed plastic bags at $-70^{\circ} \mathrm{C}$ after the radiological evaluation until 1 day before biomechanical testing. All left femoral and lumbar vertebra were removed from the freezer and allowed to thaw overnight in the original sealed plastic bags before biomechanical testing. Biomechanical tests were performed in a configuration that simulated the mechanical axis of the rat femur and lumbar vertebra using a universal material testing machine (QX-W550, Shanghai QiXiang Testing Instrument Co., Ltd., China), and the 


\section{Cellular Physiology Cell Physiol Biochem 2018;46:1727-1736 \\ \begin{tabular}{l|l|l} 
DOI: 10.1159/000489248 & $\begin{array}{l}\text { O } 2018 \text { The Author(s). Published by S. Karger AG, Basel } \\
\text { www.karger.com/cpb }\end{array}$ \\
\hline and Biochemistry
\end{tabular}}

Wu et al.: Icariin Restores Bone Structure and Strength of Alcohol Induced Osteopenia

vertebral body was tested in compression mode. Three-point bending test of the left femur was performed to determine the peak load, ultimate stiffness, toughness, ultimate strength, and Young's modulus. All these parameters have been described previously [37, 41, 42]. The length of the femur was measured and fixed on the testing machine. Then the actuator moved downward at a rate of $1 \mathrm{~mm} / \mathrm{s}$ until fracture occurred. The fracture position and fracture load were recorded to calculate the load-deformation curve. Finally, the biomechanical characteristics of femurs could be obtained based on the curve. The compression test of the vertebral body was also performed as described previously $[43,44]$. The vertebra was fixed on the machine compressed. The vertebral body was loaded in compression at a rate of $0.15 \mathrm{~mm} / \mathrm{s}$. The compression and deformation of the vertebral body were carefully recorded. Load-displacement curves were generated, and related parameters including the ultimate stress, maximum load, ultimate strain, and Young's modulus were calculated. All these parameters were evaluated by an expert blinded to the group and findings from the radiological evaluation according to the load-deformation curve and bone external dimensions.

\section{$R T-P C R$}

RT-PCR was used to detect the mRNA level of alkaline phosphatase (ALP), collagen type I (Col I), osteocalcin (OC), runt-related transcription factor 2 (Runx2), bone morphogenetic protein-2 (BMP-2), and osteoprotegerin (OPG). Mononuclear cells isolated from whole blood $(5 \mathrm{ml})$ were mixed with Trizol and the total RNA was extracted. RNA concentration was determined by ultraviolet spectrophotometry. Then reverse transcription was performed according to the protocol reaction conditions. Images of RT-PCR were obtained and analyzed with ABI 7500. The mRNA expression levels were normalized relative to GAPDH mRNA expression, and relative mRNA levels of ALP, Col I, OC, Runx2, BMP-2, and OPG were calculated.

\section{Statistical evaluation}

All results were expressed as the mean \pm standard deviation. The available data were analyzed using SPSS statistical software version 21.0. Comparisons between groups were performed by parametric or nonparametric analysis of variance (ANOVA) followed by Fisher's protected least significant difference test when results from ANOVA were significant. $P<0.05$ was considered to be statistically significant.

\section{Results}

\section{Evaluation of bone parameters}

No rat died during the experiment. Compared with the sham group, MAR (Fig. 1A, 1B) and \%Tb.Ar (Fig. 1C, 1D) of the alcohol group were significantly reduced $(P<0.05)$. There

Fig. 1. a: Microscopy of femurs with tetracycline fluorescence double labeling showed a statistically significant difference $(\mathrm{P}<0.05)$ in growth distance of new bone between groups. b: Histomorphology showed a statistically significant difference $(\mathrm{P}<$ 0.05 ) in MAR between groups. c: Toluidine blue staining of femur sections showed a statistically significant difference $(\mathrm{P}<0.05)$ in the area of mineralized trabecular bone between groups. $\mathrm{d}$ : Histomorphology showed a statistically significant difference $(\mathrm{P}<0.05)$ in \% Tb.Ar between groups. $* \mathrm{P}<0.05$.

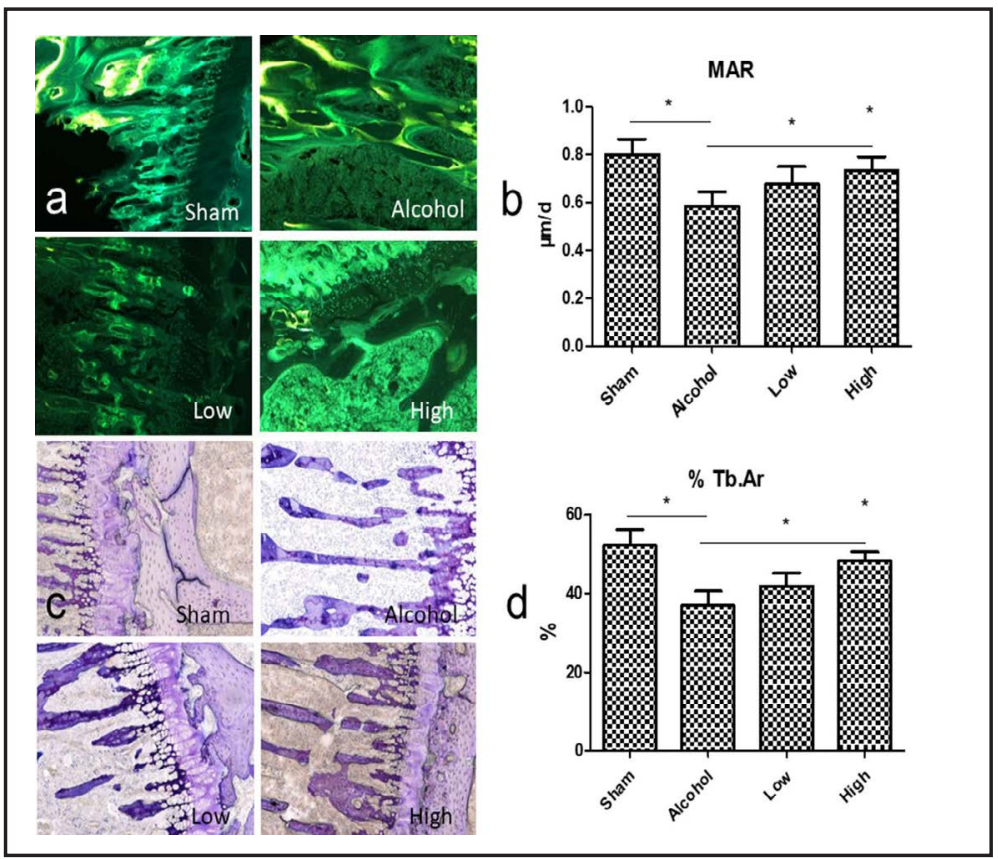

\section{KARGER}




\section{Cellular Physiology and Biochemistry

were significant differences in \% Tb.Ar and MAR $(P<0.05)$ between the lowdose icariin and the alcohol groups and between the high-dose icariin and alcohol groups (Fig. 1). Fig. 2 shows three-dimensional images of the distal femur in the different groups. The indicators that reflected bone changes are shown in Fig. 3. For the alcohol group, BV/TV, Tb.N, Tb.Sp, and BMD were significantly lower than in the sham group $(P<0.05)$ (Fig. 3). For the low-dose icariin group, BV/TV, Tb.N, Tb.Sp, and BMD were significantly higher compared with the alcohol group $(P<0.05)$ (Fig. 3). For the highdose icariin group, BV/TV, Tb.N, Tb.Sp, and BMD were significantly higher compared with the alcohol group $(P<$ 0.05) (Fig. 3). There was no statistical difference in Tb.Th among the groups (Fig. 3).

\section{Biomechanics results}

No statistically significant differences in weight were observed between the groups until the 24th week; thus, the effect of weight on the biomechanical results did not need to be taken into account. In the threepoint bending test of the left femur (Fig. 4), peak load, ultimate stiffness, toughness, ultimate strength, and Young's modulus of the alcohol group were significantly lower compared with the sham group $(P<0.05)$. Peak load, ultimate stiffness, toughness, ultimate strength, and Young's modulus were significantly higher $(P<0.05)$ in both the low-dose and high-dose icariin groups compared with the alcohol group. In the compression test of the vertebral body (Fig. 5), ultimate stress,

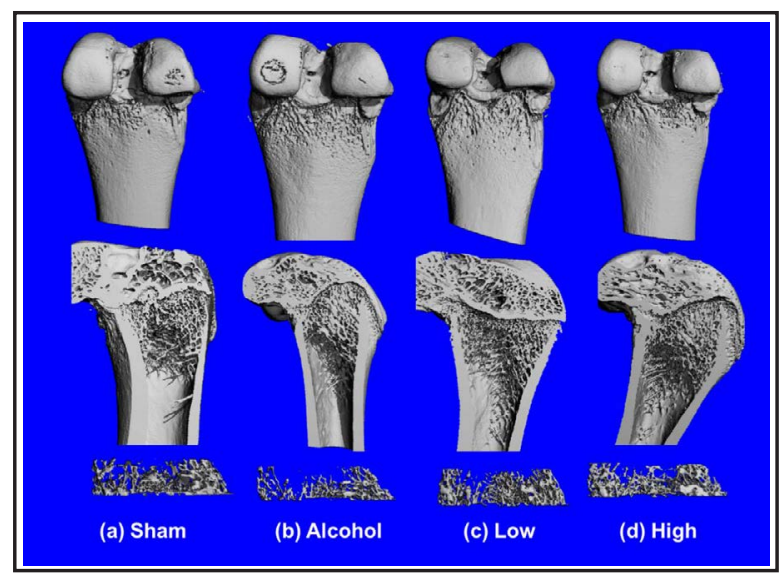

Fig. 2. Three-dimensional images of the distal femur in rats from different groups. (a): Sham group; (b): alcohol group; (c): low-dose icariin group; (d): high-dose icariin group.

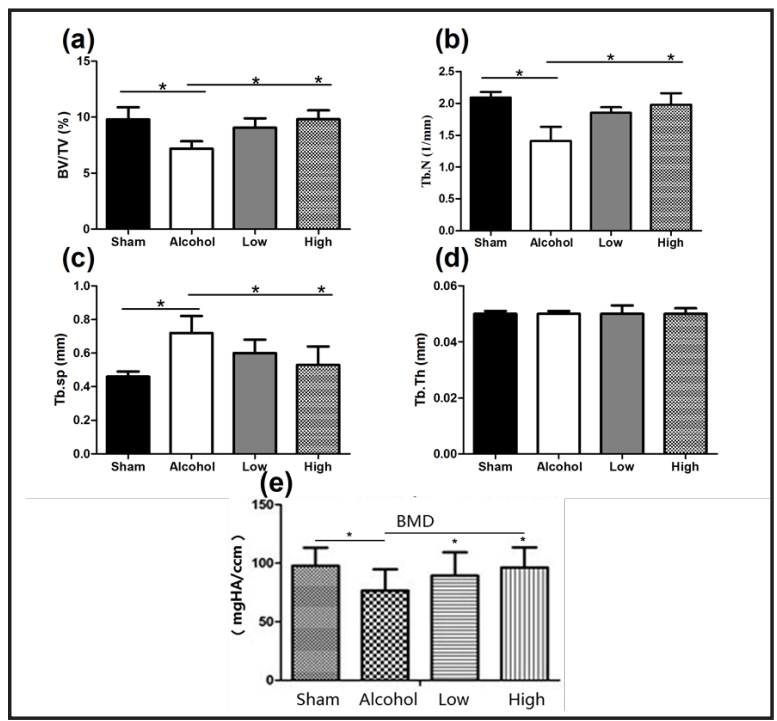

Fig. 3. (a), (b), (c), and (e): Micro-CT showing a statistically significant difference $(\mathrm{P}<0.05)$ in BV/TV, Tb.N, Tb.Sp, and BMD of the distal femoral metaphysis between groups. (d): Micro-CT showing no statistically significant difference in $\mathrm{Tb}$.Th of the distal femoral metaphysis between groups. * $\mathrm{P}<0.05$. maximum load, ultimate strain, and Young's modulus of the lumbar vertebra (L4) in the alcohol group were significantly lower $(P<0.05)$ than in the sham group. Ultimate stress, maximum load, and Young's modulus were significantly higher $(P<0.05)$ in the low-dose icariin group compared with the alcohol group; ultimate strain was increased but this difference did not reach statistical significance. Ultimate stress, maximum load, ultimate strain, and Young's modulus were significantly higher $(P<0.05)$ in the high-dose icariin group compared with the alcohol group.

\section{Expression of genes involved in osteoblast differentiation}

The alcohol group showed significantly reduced ALP, Col I, OC, Runx2, BMP-2, and OPG mRNA levels compared with the sham group $(P<0.01)$ (Fig. 6). The mRNA levels of ALP, 

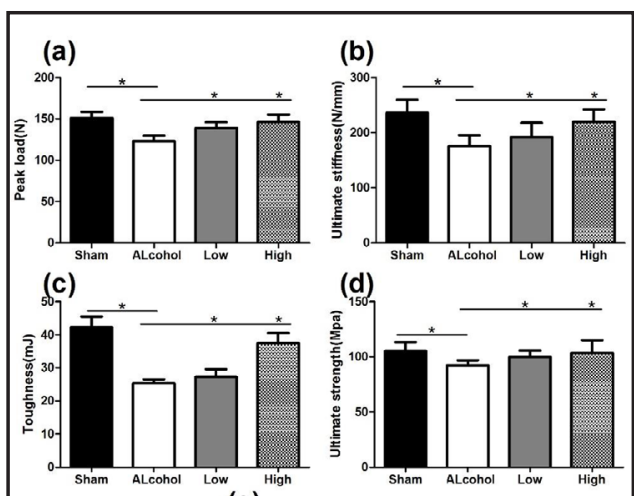

(e)

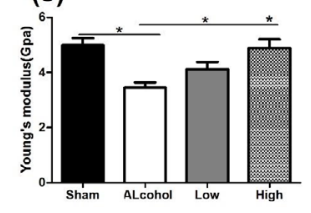

Fig. 4. Results of the three-point bending test of the left femur. (a): Peak load; (b): ultimate stiffness; (c): toughness; (d): ultimate strength; and (e): Young's modulus in each group. ${ }^{*} \mathrm{P}<$ 0.05 .

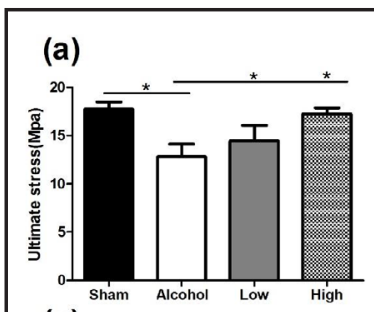

(c)
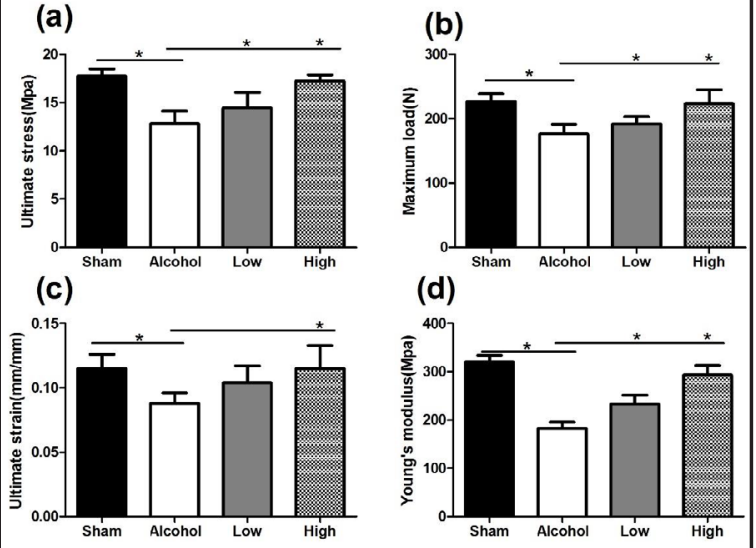

(d)

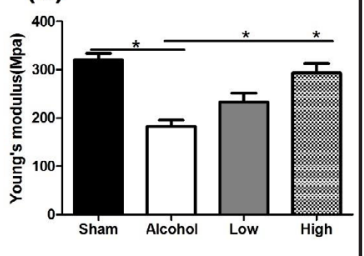

Fig. 5. Material biomechanical properties of the vertebral body (L4). (a): Ultimate stress; (b): maximum load; (c): ultimate strain; and (d): Young's modulus in each group. ${ }^{*} \mathrm{P}<0.05$.
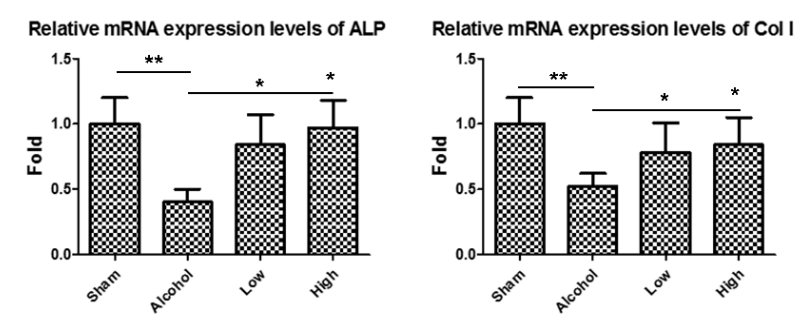

Relative mRNA expression levels of Runx
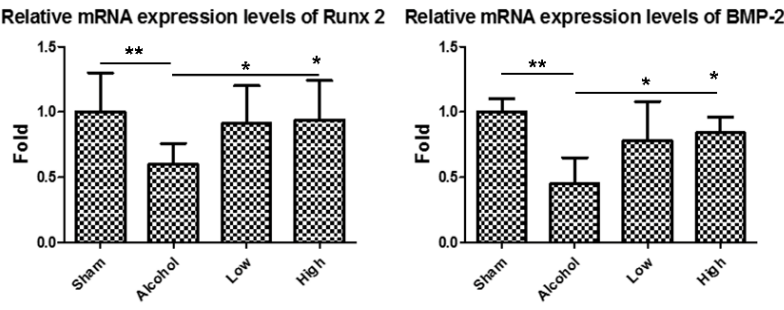

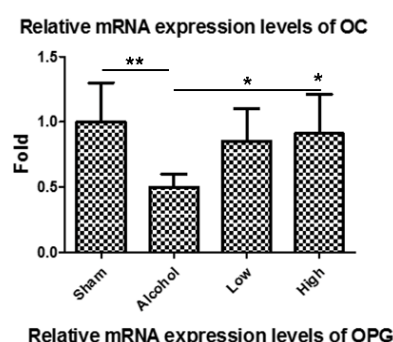

Relative mRNA expression levels of OPG

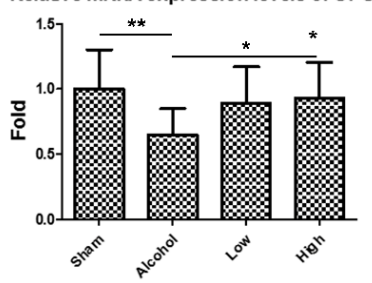

Fig. 6. Relative mRNA expression levels of ALP, Col I, OC, Runx2, BMP-2, and OPG were determined by RTPCR. ALP, alkaline phosphatase; Col I, collagen type I; OC, osteocalcin; Runx2, runt-related transcription factor 2; BMP-2, bone morphogenetic protein-2; OPG, osteoprotegerin. ${ }^{*} \mathrm{P}<0.05$; ${ }^{* *} \mathrm{P}<0.01$.

Col I, OC, Runx2, BMP-2, and OPG in the high-dose and low-dose icariin groups increased significantly compared with the alcohol group $(P<0.05)$ (Fig. 6). The mRNA levels of ALP, Col I, OC, Runx2, BMP-2, and OPG in the high-dose icariin group were elevated in comparison with the low-dose icariin group, but these differences did not reach statistical significance (Fig. 6). 


\section{Cellular Physiology Cell Physiol Biochem 2018;46:1727-1736

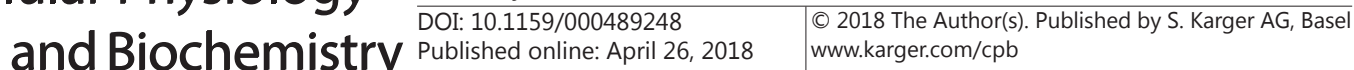

Wu et al.: Icariin Restores Bone Structure and Strength of Alcohol Induced Osteopenia

\section{Discussion}

Osteoporosis is a systemic bone metabolic disease characterized by bone mass and quality reduction along with bone tissue microarchitectural deterioration. Osteoclastmediated bone resorption is higher than osteoblast-mediated bone formation leading to bone remodeling imbalance in this bone disorder.

Icariin therapy for chronic high-dose alcohol-induced osteopenia has been assessed in this study. Our findings demonstrate that high-dose icariin treatment prevented the decrease of BV/TV and BMD and also restored bone biomechanical quality in chronic highdose alcohol-induced osteopenia. Icariin influenced the expression of ALP, Col I, OC, and OPG in the BMP-2/Runx2 signaling pathway. The mechanism of action of icariin in chronic highdose alcohol-induced osteopenia may be based on the concept of strengthening tendons and bones in traditional Chinese medicine $[45,46]$.

Compressive force and tolerance were significantly reduced in the alcohol group compared with the sham group. The biomechanical properties of bone can be adversely affected. Under the same external stress, there will be an increased risk of osteoporotic fracture; in addition, there will be a direct toxic effect on osteoblasts and bone formation inhibition, which can lead to a lack of bone quality. Alcohol toxicity directly inhibits mineralization, resulting in lower bone mass and worse structure, and ultimately reduces bone strength. Through treatment with icariin, the adverse effect on bone biomechanics can be prevented [47]. High-dose icariin can increase bone biomechanical properties, with a greater effect than low-dose icariin.

Preliminary findings in our study revealed that both low and high doses icariin groups had higher ALP, Col I, OC, Runx2, BMP-2, and OPG expression levels compared with the alcohol group, suggesting that icariin may activate the OPG, BMP-2, and Runx2 signaling pathways. Icariin is an effective drug for the treatment of chronic high-dose alcohol-induced osteopenia and has few adverse effects, so it is worth considering for clinical application. High-dose icariin can reduce the side effects of bone metabolism caused by a decrease in the level of $\mathrm{E}_{2}$ [47].

It is found that icariin can stimulate the formation of new bone after local injection on the surface of the skull [48]. Icariin could significantly reverse bone loss induced by OPG deficiency and promote osteoblast differentiation through upregulation of BMP-2, OC, and Runx2 expression in $\mathrm{OPG}^{-/-}$mice. The expression levels of Wnt1 and Wnt3a in the lumbar vertebrae were significantly upregulated after treatment with icariin in mice with a mutation in the OPG gene. Icariin treatment in $\mathrm{OPG}^{-/-}$mice increased AXIN2, DKK1, TCF1, and LEF1 expression; these are direct target genes of the $\beta$-catenin signaling pathway. We also studied the effect of icariin on the biomechanical properties of femur and lumbar vertebrae in the chronic high-dose alcohol-induced osteopenia rat model, and found that it significantly increased the mechanical strength of these bones. In addition, in vitro studies showed that icariin activated the Wnt/ $\beta$-catenin and BMP- 2 signaling pathways to induce osteoblast differentiation [49]. A recent study by Liu et al. demonstrated that the effect of icariin on osteoblastic differentiation was via activation of Runx 2 promoter and Wnt/ $\beta$ catenin pathway [31].

BMP-2 is a strong inducer of osteoblast differentiation and bone formation [50]. In this study, BMP-2 was upregulated in the chronic high-dose alcohol-induced osteopenia rat model after treatment with icariin. BMP-2 binds to bone cell surface receptors followed by phosphorylation of smad1/5/8. Smad4 and phosphorylated smad1/5/8 form a complex and translocate to the nucleus, which regulates the transcription of the bone-specific gene [48]. Some evidence suggests that BMP-2 induces or promotes expression of Osterix and Runx2 [51], which are important transcription factors for osteoblast differentiation and bone formation [52], along with osteoblast differentiation markers such as ALP, OC, and Col I in many cell lines. BMP-2 and Runx2 have stimulatory effects on the expression levels of OC, ALP, and Col I $[52,53]$. Thus, BMP-2 and Runx2 are key molecules in the regulation 


\section{Cellular Physiology Cell Physiol Biochem 2018:46:1727-1736 and Biochemistry \begin{tabular}{l|l} 
DOI: 10.1159/000489248 & $\begin{array}{l}\text { (c) } 2018 \text { The Author(s). Published by S. Karger AG, Basel } \\
\text { www.karger.com/cpb }\end{array}$
\end{tabular}

of osteoblast differentiation [54]. It is known that the bone formation effect of icariin was induced by regulation of the BMP-2 signaling pathway and OPG/RANKL system.

In conclusion, icariin can promote bone formation and inhibit bone loss, and effectively restore bone structure and strength of femur and lumbar vertebrae in chronic high-dose alcohol-induced osteopenic rats. Bone metabolism reversal is evidenced by increased BV/ TV, BMD, MAR, \%Tb.Ar, and bone biomechanical properties, and elevated ALP, Col I, OC, Runx2, BMP-2, and OPG mRNA levels. In addition, this study showed that icariin may play an important role in improving bone quality through activing $\mathrm{Wnt} / \beta$-catenin and BMP signaling pathways.

\section{Acknowledgements}

The work of Peng-Cheng Liu is supported by the grant from the China Scholarship Council (CSC). This work was supported by the Cultivate funding project for the National Natural Science Foundation from Tongji University.

\section{Disclosure statement}

No conflict of interests exists.

\section{References}

1 Mikosch P: Alcohol and bone. Wiener Medizinische Wochenschrift 2014;164:15-24.

$>2$ Vestergaard P, Rejnmark L, Mosekilde L: Socioeconomic aspects of fractures within universal public healthcare: a nationwide case-control study from Denmark. Scand J Public Health 2006;34:371-377.

-3 Gomez NR: [Prevalence of risk factors for fragility fracture in men aged 40 to 90 years of a Spanish basic Rural Health Area]. Rev Esp Salud Publica 2011;85:491-498.

-4 Audran M, Cortet B: [Prevalence of osteoporosis in male patients with risk factors]. Presse Med 2011;40:e489-e498.

5 Legroux-Gerot I, Blanckaert F, Solau-Gervais E, Negahban M, Duquesnoy B, Delcambre B, Cortet B: Causes of osteoporosis in males. A review of 160 cases. Rev Rhum Engl Ed 1999;66:404-409.

6 Laitinen K, Valimaki M: Alcohol and bone. Calcif Tissue Int 1991;49:S70-S73.

7 Suh KT, Kim SW, Roh HL, Youn MS, Jung JS: Decreased osteogenic differentiation of mesenchymal stem cells in alcohol-induced osteonecrosis. Clin Orthop Relat Res 2005:220-225.

8 Wang Y, Li Y, Mao K, Li J, Cui Q, Wang GJ: Alcohol-induced adipogenesis in bone and marrow: a possible mechanism for osteonecrosis. Clin Orthop Relat Res 2003:213-224.

$\rightarrow 9$ Friday KE, Howard GA: Ethanol inhibits human bone cell proliferation and function in vitro. Metabolism 1991;40:562-565.

10 Chavassieux P, Serre CM, Vergnaud P, Delmas PD, Meunier PJ: In vitro evaluation of dose-effects of ethanol on human osteoblastic cells. Bone Miner 1993;22:95-103.

11 Dai J, Lin D, Zhang J, Habib P, Smith P, Murtha J, Fu Z, Yao Z, Qi Y, Keller ET: Chronic alcohol ingestion induces osteoclastogenesis and bone loss through IL-6 in mice. J Clin Invest 2000;106:887-895.

12 Chu AJ, Nguyen CT: Ethanol inhibits phosphatidylcholine and phosphatidylethanolamine biosynthesis in human leukemic monocyte-like U937 cells. Cell Biochem Funct 1993;11:107-117.

13 Ma HP, Ma XN, Ge BF, Zhen P, Zhou J, Gao YH, Xian CJ, Chen KM: Icariin attenuates hypoxia-induced oxidative stress and apoptosis in osteoblasts and preserves their osteogenic differentiation potentialin vitro. Cell Proliferat 2014;47:527-539.

14 Maurel DB, Boisseau N, Benhamou CL, Jaffre C: Alcohol and bone: review of dose effects and mechanisms. Osteoporos Int 2012;23:1-16.

-15 Ronis MJ, Mercer K, Chen JR: Effects of nutrition and alcohol consumption on bone loss. Curr Osteoporos Rep 2011;9:53-59. 


\section{Cellular Physiology Cell Physiol Biochem 2018;46:1727-1736 \begin{tabular}{l|l} 
and Biochemistry & $\begin{array}{l}\text { DOI: 10.1159/000489248 } \\
\text { (c) } 2018 \text { The Author(s). Published by S. Karger AG, Basel } \\
\text { www.karger.com/cpb }\end{array}$
\end{tabular}

Leslie WD, Morin SN: Osteoporosis epidemiology 2013: implications for diagnosis, risk assessment, and treatment. Curr Opin Rheumatol 2014;26:440-446.

17 Svedbom A, Ivergard M, Hernlund E, Rizzoli R, Kanis JA: Epidemiology and economic burden of osteoporosis in Switzerland. Arch Osteoporos 2014;9:187.

-18 Svedbom A, Hernlund E, Ivergard M, Compston J, Cooper C, Stenmark J, McCloskey EV, Jonsson B, Kanis JA: Osteoporosis in the European Union: a compendium of country-specific reports. Arch Osteoporos 2013;8:137.

19 Qu B, Ma Y, Yan M, Wu HH, Fan L, Liao DF, Pan XM, Hong Z: The economic burden of fracture patients with osteoporosis in western China. Osteoporos Int 2014;25:1853-1860.

-20 Abukhadir SS, Mohamed N, Mohamed N: Pathogenesis of alcohol-induced osteoporosis and its treatment: a review. Curr Drug Targets 2013;14:1601-1610.

-21 Mercer KE, Wynne RA, Lazarenko OP, Lumpkin CK, Hogue WR, Suva LJ, Chen JR, Mason AZ, Badger TM, Ronis MJ: Vitamin D supplementation protects against bone loss associated with chronic alcohol administration in female mice. J Pharmacol Exp Ther 2012;343:401-412.

22 Leung PC, Siu WS: Herbal treatment for osteoporosis: a current review. J Tradit Complement Med 2013;3:82-87.

23 An J, Yang H, Zhang Q, Liu C, Zhao J, Zhang L, Chen B: Natural products for treatment of osteoporosis: The effects and mechanisms on promoting osteoblast-mediated bone formation. Life Sci 2016;147:46-58.

24 Xu F, Ding Y, Guo Y, Liu B, Kou Z, Xiao W, Zhu J: Anti-osteoporosis effect of Epimedium via an estrogen-like mechanism based on a system-level approach. J Ethnopharmacol 2016;177:148-160.

25 Ma HP, Ming LG, Ge BF, Zhai YK, Song P, Xian CJ, Chen KM: Icariin is more potent than genistein in promoting osteoblast differentiation and mineralization in vitro. J Cell Biochem 2011;112:916-923.

-26 Hsieh TP, Sheu SY, Sun JS, Chen MH, Liu MH: Icariin isolated from Epimedium pubescens regulates osteoblasts anabolism through BMP-2, SMAD4, and Cbfa1 expression. Phytomedicine 2010;17:414-423.

-27 Nian H, Ma MH, Nian SS, Xu LL: Antiosteoporotic activity of icariin in ovariectomized rats. Phytomedicine 2009;16:320-326.

28 Mok SK, Chen WF, Lai WP, Leung PC, Wang XL, Yao XS, Wong MS: Icariin protects against bone loss induced by oestrogen deficiency and activates oestrogen receptor-dependent osteoblastic functions in UMR 106 cells. Br J Pharmacol 2010;159:939-949.

29 Chen KM, Ge BF, Ma HP, Liu XY, Bai MH, Wang Y: Icariin, a flavonoid from the herb Epimedium enhances the osteogenic differentiation of rat primary bone marrow stromal cells. Pharmazie 2005;60:939-942.

-30 Zhang G, Qin L, Shi Y: Epimedium-derived phytoestrogen flavonoids exert beneficial effect on preventing bone loss in late postmenopausal women: a 24-month randomized, double-blind and placebo-controlled trial. J Bone Miner Res 2007;22:1072-1079.

-31 Liu Y, Huang L, Hao B, Li H, Zhu S, Wang Q, Li R, Xu Y, Zhang X: Use of an Osteoblast Overload Damage Model to Probe the Effect of Icariin on the Proliferation, Differentiation and Mineralization of MC3T3-E1 Cells through the Wnt/beta-Catenin Signalling Pathway. Cell Physiol Biochem 2017;41:1605-1615.

-32 Maddalozzo GF, Turner RT, Edwards CH, Howe KS, Widrick JJ, Rosen CJ, Iwaniec UT: Alcohol alters whole body composition, inhibits bone formation, and increases bone marrow adiposity in rats. Osteoporos Int 2009;20:1529-1538.

33 Shen CL, Syapin PJ, Graef JL, Smith BJ, Brackee G, Fowler AF, Segura-Ulate I, Wang J, Bergeson SE: Alcoholinduced bone loss and quality during adolescence is improved by green tea polyphenols. J Clin Toxicol 2013;7:4.

34 Broulik PD, Vondrova J, Ruzicka P, Sedlacek R, Zima T: The effect of chronic alcohol administration on bone mineral content and bone strength in male rats. Physiol Res 2010;59:599-604.

- 35 Bouxsein ML, Boyd SK, Christiansen BA, Guldberg RE, Jepsen KJ, Müller R: Guidelines for assessment of bone microstructure in rodents using micro-computed tomography. J Bone Mineral Res 2010;25:1468.

-36 Ulrich D, Van RB, Laib A, Ruegsegger P: The ability of three-dimensional structural indices to reflect mechanical aspects of trabecular bone. Bone 1999;25:55-60.

-37 Khajuria DK, Razdan R, Mahapatra DR, Bhat MR: Osteoprotective effect of propranolol in ovariectomized rats: a comparison with zoledronic acid and alfacalcidol. J Orthop Sci 2013;18:832-842.

38 Khajuria DK: Comparative Pharmacological Evaluation of Ocimum sanctum and Imipramine for Antidepressant Activity. Lat Am J Pharm 2011;30:435-439.

-39 Turner CH, Burr DB: Basic biomechanical measurements of bone: A tutorial. Bone 1993;14:595. 


\section{Cellular Physiology Cell Physiol Biochem 2018;46:1727-1736 \begin{tabular}{l|l} 
DOI: 10.1159/000489248 & and Biochemistry 2018 The Author(s). Published by S. Karger AG, Basel \\
wublisherger.com/cpb
\end{tabular}

40 Khajuria DK, Disha C, Razdan R, Mahapatra DR, Bhat MR: Comparative Evaluation of Zoledronic Acid, Alfacalcidol and Propranolol in Pharmacological Correction of Experimental Osteoporosis. Lat Am J Pharm 2013;32:968-976.

41 Burstein AH, Reilly DT, Martens M: Aging of bone tissue: mechanical properties. J Bone Joint Surg Am Vol 1976;58:82-86.

42 Estai MA, Suhaimi F, Shuid AN, Das S, Abdullah S, Soelaiman IN: Biomechanical evaluation of fracture healing following administration of Piper sarmentosum in ovariectomised rats. Afric J Pharm Pharmacol 2012;6:148-156.

-43 Turner CH, Roeder RK, Wieczorek A, Foroud T, Liu G, Peacock M: Variability in skeletal mass, structure, and biomechanical properties among inbred strains of rats. J Bone Mineral Res 2001;16: 532.

44 Sehmisch S, Erren M, Kolios L, Tezval M, Seidlovawuttke D, Wuttke W, Stuermer KM, Stuermer EK: Effects of isoflavones equol and genistein on bone quality in a rat osteopenia model. Phytother Res 2010;24:S168-S174.

45 Liu HD, Lin FS, Li E, Wu MS, Tong XX: [The influence of the different components of nourishing kidney herbs on osteoporosis rats]. Zhongguo Zhong Yao Za Zhi 2003;28:262-265.

-46 Zhang H, Xing WW, Li YS, Zhu Z, Wu JZ, Zhang QY, Zhang W, Qin LP: Effects of a traditional Chinese herbal preparation on osteoblasts and osteoclasts. Maturitas 2008;61:334-339.

47 Song L, Zhao J, Zhang X, Li H, Zhou Y: Icariin induces osteoblast proliferation, differentiation and mineralization through estrogen receptor-mediated ERK and JNK signal activation. Eur J Pharmacol 2013;714:15-22.

48 Cao X, Chen D: The BMP signaling and in vivo bone formation. Gene 2005;357:1-8.

49 Li XF, Xu H, Zhao YJ, Tang DZ, Xu GH, Holz J, Wang J, Cheng SD, Shi Q Wang YJ: Icariin Augments Bone Formation and Reverses the Phenotypes of Osteoprotegerin-Deficient Mice through the Activation of Wnt/ beta -Catenin-BMP Signaling. Evid Based Complement Alternat Med 2013;2013:652317.

-50 Yamaguchi A, Komori T, Suda T: Regulation of osteoblast differentiation mediated by bone morphogenetic proteins, hedgehogs, and Cbfa1 Endocr Rev 2000;21:393-411.

51 Lee MH, Kim YJ, Kim HJ, Park HD, Kang AR, Kyung HM, Sung JH, Wozney JM, Kim HJ, Ryoo HM: BMP-2induced Runx2 expression is mediated by Dlx5, and TGF-beta 1 opposes the BMP-2-induced osteoblast differentiation by suppression of Dlx5 expression. J Biol Chem 2003;278:34387-34394.

52 Nakashima K, Zhou X, Kunkel G, Zhang Z, Deng JM, Behringer RR, de Crombrugghe B: The novel zinc fingercontaining transcription factor osterix is required for osteoblast differentiation and bone formation. Cell 2002;108:17-29.

53 Parfitt AM, Drezner MK, Glorieux FH, Kanis JA, Malluche H, Meunier PJ, Ott SM, Recker RR: Bone histomorphometry: standardization of nomenclature, symbols, and units. Report of the ASBMR Histomorphometry Nomenclature Committee. J Bone Miner Res 1987;2:595-610.

-54 Cao H, Ke Y, Zhang Y, Zhang CJ, Qian W, Zhang GL: Icariin stimulates MC3T3-E1 cell proliferation and differentiation through up-regulation of bone morphogenetic protein-2. Int J Mol Med 2012;29:435-439. 